Vol. 1, No. 1, pp. 3-12, (October 2020)

Aswan University Journal of Environmental Studies (AUJES)

Online ISSN: 2735-4237, Print ISSN: 2735-4229

Journal homepage: http://aujes.aswu.edu.eg/

E-mail: AUJES@aswu.edu.eg

Mini review articles

\title{
Impact of COVID 19 Pandemic on the World Environment
}

\author{
Mohamed Nageeb Rashed ${ }^{* 1,2}$, Aliae AR Mohamed Hussein ${ }^{3}$, Asmaa M. Ismail ${ }^{4}$, Islam Galal ${ }^{5}$ \\ ${ }^{1}$ Department of Chemistry, Faculty of Science, Aswan University, Egypt \\ ${ }^{2}$ Unit of Environmental Studies and Development. Aswan University. \\ ${ }^{3}$ Department of Chest diseases and Tuberculosis, Faculty of Medicine. Assiut University. \\ ${ }^{4}$ Department of Pediatrics, Faculty of Medicine. Aswan University. \\ ${ }^{5}$ Department of Chest diseases and Tuberculosis, Faculty of Medicineiut. Aswan University.
}

Received: $28 / 8 / 2020$

Accepted: 7/9/2020

(C) Unit of Environmental Studies and Development, Aswan University

\begin{abstract}
:
The disruption caused by the COVID-19 pandemic worldwide has resulted in numerous impacts on the environment and the climate. As a result of the Covid-19 pandemic; water bodies, the atmosphere and ecosystems are all affected, and have experienced significant positive and negative impacts. Human health during this pandemic is the primary concern to address. Environmental systems, including water, have perceived positive impacts as a result of the reduction of pollutant loading from input of vehicle emission, and industries. This result to also, reduction in coliform and biochemical oxygen demand in rivers and lakes. Moreover, positive impacts, including air quality improvement as a result of a reduction in the loading of particulate matter, nitrous oxide, and other gaseous pollutants. In this study, we will discuss the role of different environmental factors and conditions in COVID-19 transmission, and their effect on human health.
\end{abstract}

Keywords: COVID 19; pollution; bronchial asthma; chest infection; children; viral transimaion

\section{The Interrelation between COVID-19 Pandemic, Water and Wastewater}

The provision of safe water, waste management, sanitation, and hygienic conditions is essential for protecting human health during novel coronavirus disease (COVID-19). According to the WHO report (2020), no indication that the COVID19 virus can persist in drinking water, and that for wastewater, some recent studies have found RNA fragments but not an infectious virus in wastewater. Filters and disinfectants were used in drinking water treatment plants to remove germs, and the virus that causes COVID-19.

It has been observed in the last decades that the anthropogenic and industrialization activities cause air effluence. As a result of the COVID-19 pandemic, human life comes to a standstill as many countries shut themselves off from the work.

Corresponding authors*: E-mail addresses: mnrashed@ @otmail.com 
For the first time in modern history, all types of people's activities, industries, and vehicle movement suddenly have been shut off for at least a month or more in many portions of the world. So, according to this facts, reduction of air and surface water pollution were specified in all the world (Bhowmick et al.,2020).

Sewer systems and freshwater sources in hospitals or public places may be contaminated with COVID-19 (Casanova et al.,2009). The transmission of SARS-CoV-2 like human waste contaminated waste-water sources can cause further implications in restricting the COVID-19 outbreak. Some researchers have been reported viral RNA fragments of SARS-CoV-2 in the fecal particles of infected patients, which indicate that the indirect transmission of contaminated fomites may also play a crucial role in spreading COVID-19. Chlorination and UV irradiation treatment in wastewater are expected to be capable of eradicating SARS-CoV-2 (Mallapaty,2020; Lesté-Lasserre 2020).

Ali et al. (2020) studied suspended particulate in the Vembanad Lake, India, and found that its level during the lock-down period decreased by $15.9 \%$ compared with the pre-lock-down period, while when compared with preceding years, the suspended particulate percentage decrease since April 2020 up to 34\% from the previous one.

In Venice, canal water was cleared with a greater flow rate of water; this as a consequence of the sediment settling resulted from a decrease of boat traffic, and the decrease in air pollution along the waterways (CNN,2020).

WHO recommend the hand-washing with water and soap as the best way of limiting the transmission of COVID19 virus. Many health agencies are recommending washing hands up to 8-10 times/day for 20 seconds. this implies a water requirement of 8-10 L/day, as well as soap and drying facilities (Staddon et al.2020). This fact of washing hands will cause to high consumption of freshwater and consequently cause a shortening of water.

\subsection{Transmission of COVID-19 contamination scenario in the urban and rural water cycle with potential human exposure}

Figure 1 shows the transmission of COVID-19 through the urban and rural water cycle with human exposure. It includes 15 steps (Bhowmick et al. 2020) as follows: -

1- COVID-19 spread to humans in contact with infected animals.

2- It enters the sewer system through the urine, and feces of the infected individual.

3- Hospital centers.

4- Transfer of waste-water from in-situ treatment facilities of the hospital center and reaching the sewerage system.

5- Mis-handling of biomedical wastes causing water contamination.

6- Waste-water generated from the public places

7- Treated waste-water discharge to the water bodies.

8- Bypassing of untreated wastewater directly into the receiving water bodies.

9- Direct consumption of contaminated water by rural people.

10- Contaminated water if properly disinfected/treated in water treatment plants can curb the spread of COVID-19.

11- Direct consumption of contaminated water by the urban people bypassing the water treatment line.

12-Untreated water consumption can infect healthy people. 
13- Human exposure to COVID-19 through toilet flushing and defective indoor plumbing systems.

14- Rainwater and snowmelt can cause the spreading of COVID-19 during major wet weather events.

15- Community spreading of COVID-19.

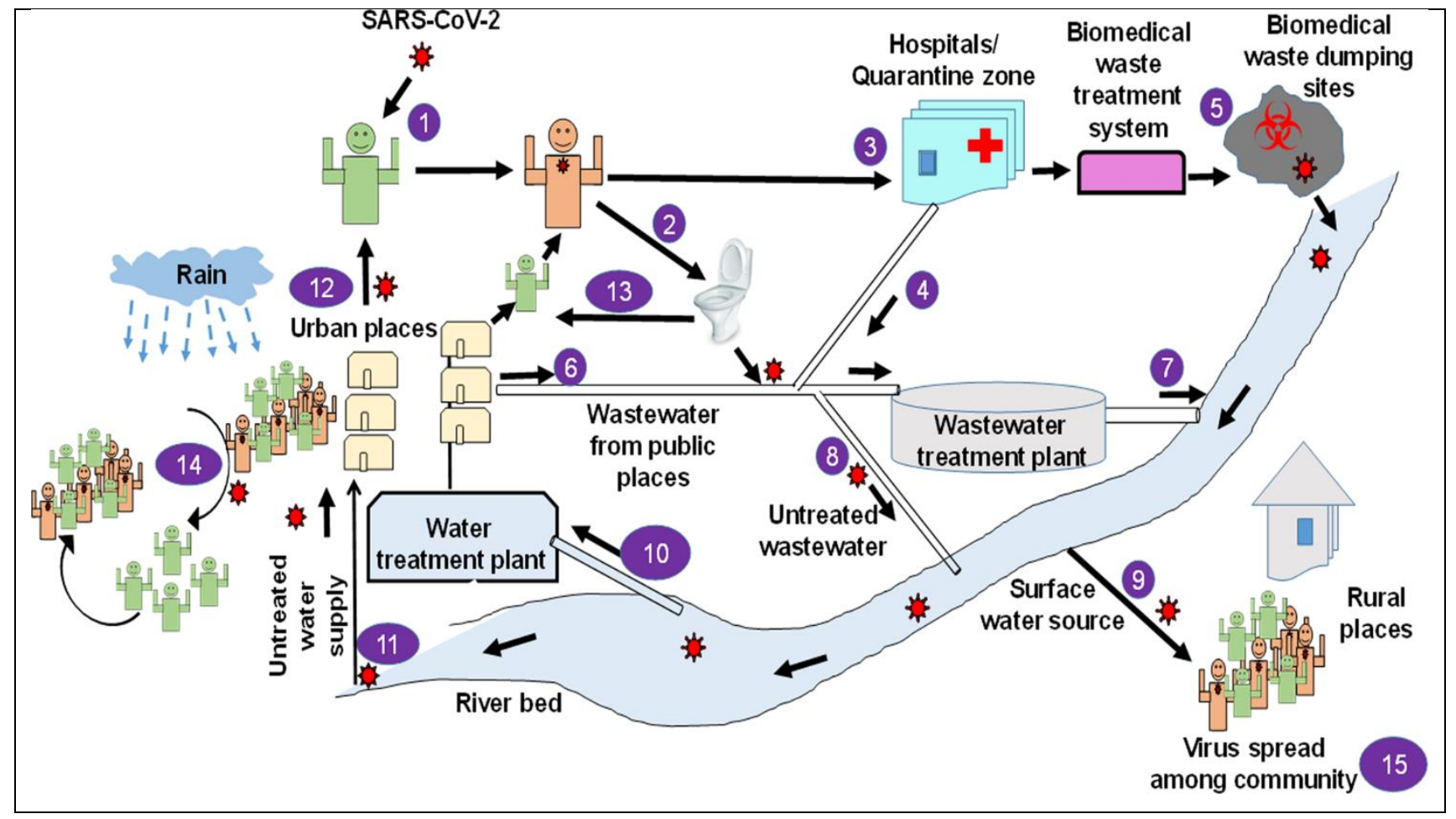

Fig.1. Contamination scenario of COVID-19 in the rural and urban water cycle with potential human exposure (Bhowmick et al.2020)

\section{Environment and COVID-19 in Children}

On 1 February 2020, it was established by The World Health Organization (WHO) that COVID-19 is a community health crisis of universal misery (WHO, 2020). Initial data supposed that severe respiratory manifestations, appear mainly in adults, with limited initial data on the load of COVID-19 on kids (Wang and Su ,2020; Wang et al., 2020).

Children are not at the maximum risk for COVID-19. Health measures concerning severe illness, essential public pandemic will have unintended consequences for the health and wellbeing of the nation's at-risk children. School closures, reduction in health-care services, social distancing, and universal public health messaging are just some of the events intended to slow the COVID-19 spread (Dong et al., 2020). It is possible that certain climatic factors may contribute to the evolution of the epidemic (Sajadi et al., 2020).

Children may play a significant role in community-based viral transmission and may have more upper respiratory tract rather than lower respiratory tract involvement as proved by available data (Dong et al., 2020). Evidence of several weeks of fecal flaking in the stool after diagnosis of COVID-19 (Jiehao et al., 2020) leading to concern about fecal-oral transmission of the virus, particularly for infants and children who are not toilet-trained, and for viral reproduction in the gastrointestinal tract (Xiao et al., 2020). 
The under-five years children, both worldwide and in developing countries, are the most susceptible groups for COVID-19 contagious compared to any additional age groups. In 2018, an estimated 5.3 million children under the age of 5 years died, mostly from avoidable childhood morbidities. For that very reason, areas with these symptoms are vulnerable/risk zone for the COVID-19 deaths in the future (Bashir et al., 2020).

There are several previous kinds of research that have deliberate the indirect effect of the COVID-19 on-air effluence (Fattorini and Regoli, 2020), and few studies have analyzed the effect of lock-down through the COVID-19 outbreak on air quality in India and noticed that improvement of air quality (PM2.5) during the COVID-19 lock-down had the highest decrease in most of the regions among the COVID-19 lock-down (Sharma et al., 2020); for a second time, PM2.5 and PM10 concentrations over Delhi, have condensed by above $50 \%$ in comparison to that before-lock-down period in India (Mahato et al., 2020).

Children are affected by indoor air pollution, and the indoor biomass combustion. The air pollutants which are emitted include suspended particulate matter, carbon monoxide, nitrogen oxides, benzene, methanol, polycyclic aromatic hydrocarbons, 1,3-butadiene, and several toxic organic compounds (Air Quality Expert Group, 2017). The cooking fuels (animal dung, wood charcoal, lignite, coal, straw, shrubs, grass, and agricultural crop) mostly used in a rural home and also in urban areas are sufficient for the awareness of indoor air pollutants (Iips, 2017). Cigarette smoking, videos, and pipes within the home or indoor environment are also other liable factors for the increase of indoor pollution (Chaouachi, 2009), a common risk element of the Coronavirus disease among children under five years.

\section{The Interrelation between COVID-19, Atmosphere and Chest Diseases}

Initially described in China in December 2019, a severe respiratory disorder caused by corona virus 2 (SARS-CoV-2) has spread all over the world. By the end of March 2020, there was an emergent numeral of 823,626 established cases and 40,598 losses stated to the WHO (WHO, 2020). The virus had spread like rough spirit during three months affecting all the global regions, nowadays there was proved, 20.6 million confirmed cases of COVID-19, as well as over $749 \mathrm{~K}$ deaths worldwide. Egypt reported slightly over 95.963000 confirmed COVID-19 cases with 5085 deaths (Ministry of Health and Population Egypt, 2020).

\subsection{The Interrelation between COVID-19 and the Atmosphere}

COVID-19 pandemic has a considerable effect on several aspects of our life. The interrelation between COVID-19 and the atmosphere is an emergent research issue. Although COVID-19 is triggering marked injury to frugality and civilizations, it has improved the environment as effluence has reduced substantially (Chakraborty and Maity, 2020). COVID-19 aids to improve the atmosphere and generate an optimistic consequence on the atmosphere. Daily global carbon emissions during the lock-down measures in early April was 17\% and could lead to an annual carbon emissions decline of up to $7 \%$, which would be the biggest drop since World War II. According to the researchers, they ascribe these declines mainly to the reduction of transportation usage and industrial activities as an influence of COVID-19 outbreak (NBC News 2020).

Owing to COVID-19, administrations have forced limitations on the mobility of the publics, cars, travel, and suspended manufacturing actions. This led to a drop in air pollution (Zhang et al. 2020; Quéré et al.2020). The significances of such lock-downs have been 
noteworthy, as per airborne-effluence ranks have fallen ominously; for example, conservatory vapor releases, nitrogen dioxide, dark carbon, and water effluence have extremely reduced (Zambrano-Monserrate et al, 2020).

Pollution loads to the environment decreased as a result of lock-down industrial activities and people's movements through COVID 19 period. As expected, the carbon emissions level has dropped significantly (Stone 2020). Air quality in China went up 11\% in the category 'good' in as many as 337 cities, according to the Ministry of Ecology and Environment, China (Henriques 2020). The use of fossil fuel would decline by about $10 \%$ around the world owing to the COVID19 spread (SCRIPPS 2020). The improvements in environmental pollution are considered to be temporary, the current level of pollution in the atmosphere, biosphere, and hydrosphere could be much lower than the pre-COVID-19 period.

Several studies stated that anthropogenic activities are considered as one of the key drivers of pollution in all spheres of the environment (Schlacher et al. 2016). Yongjian et al, (2020) found ominously positive relations of $\mathrm{PM}_{2.5}, \mathrm{PM}_{10}, \mathrm{CO}, \mathrm{NO}_{2}$, and $\mathrm{O}_{3}$ with COVID-19 definite cases, whereas $\mathrm{SO}_{2}$ was adversely allied with the figure of regular definite cases. These results might afford proof that air contamination is a significant issue in COVID-19 contagion. Furthermore, Muhammad et al, (2020) reported that that environmental pollutant such as PM10, PM2.5, SO2, NO2, and CO have a significant correlation with the COVID-19 epidemic in California.

\subsection{The interrelation between COVID-19, Air Pollution and Chest Diseases}

Air effluence is acknowledged to origin impairment to numerous tissues and organ systems, excluding the respiratory and cardiovascular systems, as there were above 4 million deceases (7.6\% of total international deceases) in 2015 was attributed to it (Forouzanfar,2016). Air effluence is considered a chief issue in determining the magnitude and mortality of COVID19 in extremely contaminated zones worldwide (Iriti et al, 2020). The considerable decline in planned travel has caused many regions to experience a large drop in air effluence. The current eruption of the novel coronavirus disease 2019 (COVID-19) in more than 250 countries has become a serious threat to the health of societies around the world.

\subsubsection{The Interrelation with Bronchial Asthma}

Bronchial asthma is one of the most corporate protracted illnesses in children, distressing one out of 12- teen-aged children in the United States (Zahran et al, 2018). Toxic waste and respiratory virus exposure can deteriorate asthma complaints and provoke exacerbations (Bush, 2019). Viral respiratory infections are also concomitant with a large number of asthma exacerbations in pediatrics (Jartti and Gern, 2017), and individuals with asthma presented with further complicated, persistent respiratory viral contagions than those individuals devoid of asthma (Corne et al., 2002). In Philadelphia, Taquechel et al. (2020) found that the community health interferences planned to frontier the COVID-19 spread were allied with augmented videotelemedicine and reduced global bronchial asthma health-care visit records and encounter kinds, systemic steroid recommendations, and the number of rhino-virus positive cases in their emergency department, furthermore they summarized that the levels of 4 standards air contaminants comprising (PM 2.5, PM10, $\mathrm{NO}_{2}$ and $\mathrm{O}_{3}$ levels) did not ominously alter during the COVID -19 outbreak paralleled to ancient records. 
An added issue that might have attributed to the condensed asthma illness load and health-care consumption after COVID-19 is augmented application of protective procedures comprising communal separation and amplified time consumed at home may have restricted individual exposure to viruses and out-door contamination decreasing exposure to out-door ecological allergens that are known prompts of pediatric asthma (Wisniewski et al.,2016). Exposure to allergens was decreased due to schools shutting, as institute atmospheres can be bases of exacerbators that rise asthma severity (Gaffin et al.,2018; Esty et al.,2019).

\subsubsection{The Interrelation with Respiratory Infections}

As established by preceding manuscripts, air effluence is also strictly associated with lung contagion triggered through other microbes (Ciencewicki and Jaspers, 2007; Mehta et al., 2013). Xie et al, (2019) also found a substantial relationship of distinctive particulate material $\left(\mathrm{PM}_{2.5}\right.$ and $\left.\mathrm{PM}_{10},\right)$ and the need for hospital admission for respiratory illness via a distributed lag nonlinear model. Another study piloted in Thailand detected that $\mathrm{PM}_{10}, \mathrm{SO}_{2}, \mathrm{CO}, \mathrm{NO}_{2}$, and $\mathrm{O}_{3}$ were ominously linked to the augmented hazard of hospital admittance due to lung diseases (Phosri et al.,2019). Horne et al. (2018) described that short-range acquaintance to greater $\mathrm{PM}_{2.5}$ was allied with additional health-care encounters for serious lower respiratory contagions. Furthermore, Chen et al, (2007) revealed that acquaintance to $\mathrm{SO}_{2}, \mathrm{CO}$, and $\mathrm{NO}_{2}$ was injurious to our well-being and augmented the possibility of breathing problems. Generally, all of the 6 air contaminants could be considered hazard elements in respiratory contagion. Conversely, Yongjian et al., (2020) conclusions are dissimilar from earlier studies as they perceived an undesirable association between $\mathrm{SO}_{2}$ and COVID-19 established cases.

\subsubsection{The Interrelation with COPD}

Community health reviews have allied climate suspended matter, nitrogen dioxide and further air contaminants acquaintance to immunologic disorders of the breathing system [bronchial asthma and chronic obstructive pulmonary disease (COPD)], disorders related to atopy, sensitization reactions, and eczema (Morgenstern et al, 2008). Moreover, COPD has also been linked with an atypical respiratory and systemic immune reaction to smoking (Cruz et al, 2019). Similarly, Roca et al, (2013) summarized that smoking, bio-mass sweltering, air effluence, and breathing of fine dust materials are donating aspects to COPD pathogensis. Smokers and COPD cases are sub-populations with an augmented hazard of complicated COVID-19, probable owing to the greater airway expression of angiotensin-converting enzyme 2 (ACE2) receptor, the entrance receptor for this novel virus, in lung (Leung et al, 2020). Therefore, numerous COVID19 cases with COPD progress to acute respiratory distress syndrome (ARDS). They also have multi-organ destruction, replicating serious systemic inflammatory reaction and promote several organ failure (Docea et al, 2020).

\section{4- References}

Air Quality Expert Group (2017). The Potential Air Quality Impacts from Biomass Combustion. Report. Department for Environment, Food and Rural Affairs; Scottish Government; Welsh Government; and Department of the Environment in Northern Ireland.

Ali, P. Yunus, Yoshifumi Masago and Yasuaki Hijiok (2020). COVID-19 and surface water quality: Improved lake water quality during the lockdown. Science of the Total Environment, 731: 139012. 
Bashir M. F. Bilal, B. M. and Komal B. (2020). Correlation between Environmental Pollution Indicators and COVID-19 Pandemic: A Brief Study in Californian Context. Environmental Research, 187:109652.

Bhowmick, G.D., Dhar, D. and Nath, D. (2020). Coronavirus disease (COVID-19) outbreak: some serious consequences with urban and rural water cycle. Clean Water 3, 32.

Bush A. (2019). Pathophysiological mechanisms of asthma. Frontiers in pediatrics. 19;7:68.

Casanova, L., Rutala, W. A., Weber, D. J. and Sobsey, M. D. (2009). Survival of surrogate coronaviruses in water. Water Res. 43, 1893-1898.

Chakraborty, I., and Maity, P. (2020). COVID-19 outbreak: Migration, effects on society, global environment and prevention. Science of the Total Environment, 728:138882.

Chaouachi, K. (2009). Hookah (shisha, narghile) smoking and environmental tobacco smoke (ETS). A critical review of the relevant literature and the public health consequences. International Journal of Environmental Research and Public Health, 6(2), 798-843.

Canadell, Josep G. and Friedlingstein, Pierre (2020). Temporary reduction in daily global $\mathrm{CO}_{2}$ emissions during the COVID-19 forced confinement. Nature Climate Change. 10 (7): 647653.

Chauhan A.J.and Johnston S.L (2003). Air pollution and infection in respiratory illness. British medical bulletin. 1;68(1):95-112.

Chen, T. M., Kuschner, W. G., Gokhale, J., and Shofer, S. (2007). Outdoor air pollution: nitrogen dioxide, sulfur dioxide, and carbon monoxide health effects. The American journal of the medical sciences, 333(4), 249-256.

Ciencewicki, J., and Jaspers, I. (2007). Air pollution and respiratory viral infection Inhalation toxicology, 19(14), 1135-1146.

Corne, J. M., Marshall, C., Smith, S., Schreiber, J., Sanderson, G., Holgate, S. T., and Johnston, S. L. (2002). Frequency, severity, and duration of rhinovirus infections in asthmatic and non-asthmatic individuals: a longitudinal cohort study. The Lancet, 359(9309), 831-834.

CNN. (2020) "Jellyfish seem swimming in Venice's canals". Retrieved 25 April 2020. https://edition.cnn.com/travel/article/jellyfish-venice/index.html .

Cruz Santa Cruz, T., López Giraldo, A., Noell, G., Casas Recasens, S., Garcia, T., Molins LópezRodó, L., and Faner, R. (2019). Multi-level immune response network in mild-moderate Chronic Obstructive Pulmonary Disease (COPD). Respiratory Research, 20, p. 152.

Docea, A. O., Tsatsakis, A., Albulescu, D., Cristea, O., Zlatian, O., Vinceti, M. and Dumanov, J. M. (2020). A new threat from an old enemy: Re-emergence of coronavirus. International journal of molecular medicine, 45(6), 1631-1643.

Dong Yuanyuan, Xi Mo, Yabin Hu, Xin Qi, Fan Jiang, Zhongyi Jiang' and Shilu Tong. (2020). Epidemiology of COVID-19 Among Children in China: Pediatrics: 145(6):20200702

Esty, B., Permaul, P., DeLoreto, K., Baxi, S. N., and Phipatanakul, W. (2019). Asthma and allergies in the school environment. Clinical Reviews in Allergy \& Immunology, 57(3), 415-426.

Fattorini D., and Regoli F., (2020). Role of the Chronic Air Pollution levels in the Covid-19 Outbreak Risk in Italy. Environmental Pollution.264: 114732. 
Forouzanfar, M. H., Afshin, A., Alexander, L. T., Anderson, H. R., Bhutta, Z. A., Biryukov, S., and Cohen, A. J. (2016). Global, regional, and national comparative risk assessment of 79 behavioural, environmental and occupational, and metabolic risks or clusters of risks, 1990-2015: a systematic analysis for the Global Burden of Disease Study 2015. The lancet, 388(10053), 1659-1724.

Gaffin, J. M., Hauptman, M., Petty, C. R., Sheehan, W. J., Lai, P. S., Wolfson, J. M., and Phipatanakul, W. (2018). Nitrogen dioxide exposure in school classrooms of inner-city children with asthma. Journal of Allergy and Clinical Immunology, 141(6), 2249-2255.

Henriques, M. (2020). Will Covid-19 have a lasting impact on the environment. BBC News. Horne, B. D., Joy, E. A., Hofmann, M. G., Gesteland, P. H., Cannon, J. B., Lefler, J. S., and Kartchner, D. (2018). Short-term elevation of fine particulate matter air pollution and acute lower respiratory infection. American journal of respiratory and critical care medicine, 198(6), 759-766.

Iips, I.C.F. ( 2017). National Family Health Survey (NFHS-4), 2015-16. International Institute for Population Sciences (IIPS), Mumbai, India. http://rchiips.org/nfhs/ NFHS4.Reports/India.pdf.

Iriti, M., Piscitelli, P., Missoni, E., and Miani, A. (2020). Air Pollution and Health: The Need for a Medical Reading of Environmental Monitoring Data. Int J Environ Res Public Health. 25;17(7):2174.

Jartti, T., and Gern, J. E. (2017). Role of viral infections in the development and exacerbation of asthma in children. Journal of Allergy and Clinical Immunology, 140(4), 895-906.

Jiehao Cai, Jing Xu, Daojiong Lin, Zhi Yang, Lei Xu, Zhenghai Qu,Yuehua Zhang, Hua Zhang, Ran Jia, Pengcheng Liu, Xiangshi Wang, Yanling Ge, Aimei Xia, He Tian, Hailing Chang, Chuning Wang, Jingjing Li, Jianshe Wang and Mei Zeng (2020). A Case Series of children with 2019 novel coronavirus infection: clinical and epidemiological features; $\underline{\text { Clin }}$ Infect Dis. 28;198.

Leste-Lasserre, C. (2020). Coronavirus found in Paris sewage points to early warning system. Science, 368, 6489.

Leung, J. M., Yang, C. X., Tam, A., Shaipanich, T., Hackett, T. L., Singhera, G. K., and Sin, D. D. (2020). ACE-2 expression in the small airway epithelia of smokers and COPD patients: implications for COVID-19. European Respiratory Journal, 55(5).

Iips, I.C.F.( 2017). National Family Health Survey (NFHS-4), 2015-16. International Institute for Population Sciences (IIPS), Mumbai, India. http://rchiips.org/nfhs/_ NFHS4.Reports/India.pdf.

Mahato, S., Pal, S., and Ghosh, K. G. (2020). Effect of lockdown amid COVID-19 pandemic on air quality of the megacity Delhi, India. Science of the Total Environment, 139086.

Mallapaty, S. (2020). How sewage could reveal true scale of coronavirus outbreak. Nature 580, 176-177.

Mehta, S., Shin, H., Burnett, R., North, T., and Cohen, A. J. (2013). Ambient particulate air pollution and acute lower respiratory infections: a systematic review and implications for estimating the global burden of disease. Air Quality, Atmosphere \& Health, 6(1), 69-83.

Ministry of Health and Population Egypt (2020). Management Protocol of COVID-19 patients. Version 1.4. https://www.care.gov.eg/EgyptCare/Index.aspx. 
Morgenstern, V., Zutavern, A., Cyrys, J., Brockow, I., Koletzko, S., Kramer, U., and Wichmann, H. E. (2008). Atopic diseases, allergic sensitization, and exposure to traffic-related air pollution in children. American journal of respiratory and critical care medicine, 177(12), 1331-1337.

Muhammad Farhan Bashir, Ben Jiang MA, Bilalb, Bushra Komal, Muhammad Adnan Bashird,Taimoor Hassan Farooq, Najaf Iqbalf and Madiha Bashir (2020). Correlation between environmental pollution indicators and COVID-19pandemic: A brief study in Californian context. Environmental Research .187:109652.

NBC News (2020). "Global carbon emissions dropped 17 percent during coronavirus lockdowns, scientists say". https://edition.cnn.com/travel/article/jellyfish-venice/index.html. Retrieved 30 May 2020.

Phosri, A., Ueda, K., Phung, V. L. H., Tawatsupa, B., Honda, A., and Takano, H. (2019). Effects of ambient air pollution on daily hospital admissions for respiratory and cardiovascular diseases in Bangkok, Thailand. Science of the total environment, 651, 1144-1153.

Quéré Le, Corinne; Jackson, Robert B.; Jones, Matthew W.; Smith, Adam J. P.; Abernethy, Sam; Andrew, Robbie M.; De-Gol, Anthony J.; Willis, David R.; Shan, Yuli; Canadell, Josep G.; Friedlingstein, Pierre (2020). "Temporary reduction in daily global CO2 emissions during the COVID-19 forced confinement". Nature Climate Change. 10 (7): 647-653.

Roca, M., Verduri, A., Corbetta, L., Clini, E., Fabbri, L. M., and Beghé, B. (2013). Mechanisms of acute exacerbation of respiratory symptoms in chronic obstructive pulmonary disease. European journal of clinical investigation, 43(5), 510-521.

Schlacher, T.A., Lucrezi, S., Connolly, R.M., Peterson, C.H., Gilby, B.L., Maslo, B., Olds, A.D., Walker, S.J., Leon, J.X., Huijbers, C.M., et al., 2016. Human threats to sandy beaches: a meta-analysis of ghost crabs illustrates global anthropogenic impacts. Estuar. Coast. Shelf Sci. 169, 56-73

SCRIPPS (2020). Research in the time of COVID-19. [WWW Document]. URL. https:// scripps.ucsd.edu/news/research-time-covid-19, Accessed date: 17 April 2020.

Sharma, S., Zhang, M., Gao, J., Zhang, H and Kota, S. H. (2020). Effect of restricted emissions during COVID-19 on air quality in India. Sci. Total Environ. 728: 138878.

Sajadi, M. M., Habibzadeh, P., Vintzileos, A., Shokouhi, S., Miralles-Wilhelm, F., and Amoroso, A. (2020). Temperature and latitude analysis to predict potential spread and seasonality for COVID-19. Available at SSRN 3550308.

Staddon C., M. Everard, J. Mytton, T. Octavianti, W. Powell, N. Quinn, S. M. N. Uddin, S. L. Young, J. D. Miller, J. Budds, J. Geere, K. Meehan, K. Charles, E. G. J. Stevenson, J. Vonk and J. MizniakC. (2020). Water insecurity compounds the global coronavirus crisis. Water International. 45(5), 416-422.

Stone, M. (2020). Carbon emissions are falling sharply due to coronavirus. But not for long. National Geographic.

Taquechel, K., Diwadkar, A. R., Sayed, S., Dudley, J. W., Grundmeier, R. W., Kenyon, C. C., and Hill, D. A. (2020). Pediatric Asthma Healthcare Utilization, Viral Testing, and Air Pollution Changes during the COVID-19 Pandemic. The Journal of Allergy and Clinical Immunology:, In Press, Journal Pre-proof doi: https://doi.org/10.1016/j.jaip.2020.07.057.

Wang Dawei , Bo Hu, Chang Hu, Fangfang Zhu, Xing Liu, Jing Zhang, Binbin Wang, Hui Xiang, Zhenshun Cheng, Yong Xiong, Yan Zhao, Yirong Li , Xinghuan Wang, Zhiyong 
Peng (2020). Clinical Characteristics of 138 Hospitalized Patients with 2019 Novel Coronavirus-Infected Pneumonia in Wuhan, China. JAMA. 7;323(11),1061-1069.

Wang, Q., and Su, M. (2020). A preliminary assessment of the impact of COVID-19 on environment-A case study of China. Science of the Total Environment, 728: 138915.

WHO (2020). Water, sanitation, hygiene, and waste management for SARS-CoV-2, the virus that causes COVID-19. Interim guidance 29 July 2020.

Wisniewski, J. A., McLaughlin, A. P., Stenger, P. J., Patrie, J., Brown, M. A., El-Dahr, J. M., and Heymann, P. W. (2016). A comparison of seasonal trends in asthma exacerbations among children from geographic regions with different climates. In Allergy and asthma proceedings. 37(6), 475.

Xie, J., Teng, J., Fan, Y., Xie, R., and Shen, A. (2019). The short-term effects of air pollutants on hospitalizations for respiratory disease in Hefei, China. International journal of biometeorology, 63(3), 315-326.

Xiao F.,Tang M. , Zheng X. , Liu Y., Li X. ,and Shan H. (2020). Evidence for gastrointestinal infection of SARS-CoV-2. Gastroenterol. 158,1831-183

Yongjian, Z., Jingu, X., Fengming, H., and Liqing, C. (2020). Association between short-term exposure to air pollution and COVID-19 infection: Evidence from China. Science of the total environment,727: 138704.

Zahran, H. S., Bailey, C. M., Damon, S. A., Garbe, P. L., and Breysse, P. N. (2018). Vital signs: asthma in children United States, 2001-2016. Morbidity and Mortality Weekly Report, 67(5), 149.

Zambrano-Monserrate, M. A., Ruano, M. A., and Sanchez-Alcalde, L. (2020). Indirect effects of COVID-19 on the environment. Science of the Total Environment, 728:138813.

Zhang, Ruixiong; Zhang, Yuzhong; Lin, Haipeng; Feng, Xu; Fu, Tzung-May; Wang, Yuhang (April 2020). "NOx Emission Reduction and Recovery during COVID-19 in East China". Atmosphere. 11 (4): 433. 